\title{
A IMAGINAÇÃO COMO METAFÍSICA: UMA LEITURA DO POEMA “O PERCURSO DE UM PARTICULAR”, DE WALLACE STEVENS
}

\section{IMAGINATION AS METAPHYSICS: AN INTERPRETATION OF THE POEM “THE COURSE OF A PARTICULAR", BY WALLACE STEVENS}

RESUMO: Wallace Stevens produziu uma poesia considerada difícil, distante da dicção fragmentária do primeiro Eliot tanto quanto da imagística de William Carlos Williams, apesar de compartilhar com o último o interesse pelas coisas como elas são. Sua dicção poética se caracterizou muito mais pelo interesse quase filosófico na relação entre imaginação e realidade, interesse que o levou a considerar a primeira, a "rainha das faculdades" segundo Baudelaire, como uma forma de metafísica. Expurgando dela os resquícios românticos subjetivizantes e dotando-a de capacidade de abstração e generalização, Stevens lhe dá envergadura de ontologia, na medida em que ela possibilita ao poeta tanto a apreensão

\footnotetext{
${ }^{1}$ Docente do Departamento de Letras Modernas e do Prorama de Pós-Graduação em Estudos Literários da UNESP, Campus de Araraquara, 14800-901, Araraquara, SP, Brasil; docente colaborador do Programa de Pós-Graduação em Estudos de Literatura da Universidade Federal de São Carlos - UFSCAR, 18052-780, São Carlos, SP, Brasil. alcides@fclar.unesp.br
} 
SANTOS, A. C. A imaginação como metafísica: uma leitura do poema "O percurso de um particular", de Wallace Stevens

das particularidades do mundo real quanto o desenvolvimento do pensamento lógico em direção a uma fenomenologia da percepção. Esta concepção e prática poética se acentuou ao longo da trajetória poética de Stevens e embora a crítica note algum excesso retórico nos poemas de maturidade, a sua capacidade inicial de síntese - notável em Harmonium, seu livro de estréia (1923) — é retomada nos poemas da fase final de sua produção, como mostraremos na análise do poema "0 percurso de um particular", publicado após a morte do poeta, em 1955.

PALAVRAS-CHAVE: Wallace Stevens; Imaginação; Real; Metafísica.

ABSTRACT: Wallace Stevens has produced a sort of poetry considered by many critical readers as being difficult, far from the fragmentary style of the first Eliot or William Carlos Williams's imagery, although he shared with Williams the concern with things as they really are. His poetic diction is better characterized by his quasi philosophical interest in the relation between imagination and reality, which led the poet to work with imagery, the "queen of the faculties" according to Baudelaire, and to describe it as a kind of metaphysics. By purging it from romantic subjective residues and by granting it the power of abstraction and generalization Stevens turns it into a kind of ontology, in the sense that the particularities of the world can be apprehended and the logical thought towards a phenomenology of perception can be developed through it. Such poetic conception and practice were enhanced throughout his poetic career and, although scholars criticize his rhetorical excess in some of his more mature poems, Stevens synthetic power-praiseworthy in his 1923 inaugural book of poems, Harmonium - reappears in his late poetry, as the analysis of the poem "The Course of a Particular" demonstrates.".

KEYWORDS: Wallace Stevens; Imagination; Real; Metaphysics. 
SANTOS, A. C. A imaginação como metafísica: uma leitura do poema “O percurso de um particular", de Wallace Stevens

\section{0 pensamento agindo sobre o mundo}

Considerada "difícil” e "opaca” por muitos, a poesia de Wallace Stevens possui algumas particularidades que, por vezes, podem parecer idiossincráticas ou mesmo incompreensíveis a um leitor menos afeito a um tipo de poesia reflexiva, cerebral, mas que a um olhar mais atento, revela um entrelaçamento bastante complexo de pensamento e imaginação na elaboração poética de coisas, cenas e pessoas comuns. Sob a égide da imaginação, o poeta conseguiu um grau de apuro no manuseio da linguagem suficiente para permitir a elocução poética de reflexões sofisticadas e tal apuro exige do leitor igual esmero no acompanhamento da ação do pensamento sobre o mundo, matéria-prima de sua poesia.

Apesar de compartilhar com seus contemporâneos William Carlos Williams e T. S. Eliot o apelo visual fortemente influenciado pelas vanguardas da pintura européia, sobretudo o cubismo e o surrealismo, o viés mais marcante de sua poesia é, como explica seu tradutor no Brasil, Paulo Henriques Britto, "uma modalidade discursiva, lógica, por vezes quase didática."(1987, p. 11). Tal viés levou alguns críticos a perceber que mesmo não tendo tido educação formal em Filosofia, como T. S. Eliot, por exemplo, o poeta tem uma verve filosofante muito marcada, central, diríamos mesmo, à sua poesia:

Among the great modernist poets in English, it is T. S. Eliot who, on the face of it, can lay most claim to being a philosophical poet. After all, Eliot is the only poet of his generation to have enjoyed extensive academic training in philosophy. He even wrote a doctoral dissertation in the field. Yet, [...] it is not Eliot who has gone down in history as the most philosophical of modernist poets in English. That honor has been bestowed on another Harvard student from around the turn of the century: Wallace Stevens. (EECKHOUT, 2007, p. 2406). ${ }^{2}$

\footnotetext{
2 "Entre os grandes poetas modernistas, não é T. S. Eliot quem, de fato, mais pode reclamar ser um poeta filosófico, pois Eliot é o único poeta da sua geração que usufruiu de uma formação acadêmcia extensiva em filosofia. Ele até mesmo escreveu uma tese de doutorado neste campo. Entretanto, [...] não foi Eliot quem entrou para a história como o mais filosófico dos poetas modernistas em inglês. Tal honra foi concedida a outro aluno
} 
SANTOS, A. C. A imaginação como metafísica: uma leitura do poema "O percurso de um particular", de Wallace Stevens

A verve filosofante de Stevens tem por base a influência de George Santayana, seu professor em Harvard, notadamente as suas ideias sobre a beleza como criação mental humana e sobre Deus como metáfora, não como verdade teológica ou metafísica. Muito mais, com certeza, poderia ser dito sobre a influência de The Sense of Beauty (1896) no poeta que, já em 1935, postulava o "poema do ato da mente" ("Of Modern Poetry"/ "Da Poesia Moderna”).

A concepção de Santayana da beleza como criação mental, não inerente à natureza, teve papel fundamental no primeiro livro de poemas de Stevens, Harmonium, publicado primeiramente em 1923. Nos poemas deste livro de estréia, nota-se a influência da pintura cubista e do Imagismo de Pound e $\mathrm{H}$. Doolittle em poemas que trazem uma exuberância de cores e formas, animais, coisas e personagens que em alguns poemas beira o exotismo, como em "Dominion of Black" / "Domínio do Negro" ou "Sea Surface with Clouds" / "Marinha, com Nuvens". A ênfase em uma certa exuberância da natureza denota, novamente nas palavras de Paulo Henriques Britto, a rejeição do “...transcendentalismo cristão em favor de uma religiosidade radiante da matéria, através de uma profusão de imagens deliciosas, impregnadas de uma atmosfera inebriante de lazer e luxo" (op. cit., p. 11).

A presença deste exotismo natural de índole pagã não é exclusividade de Stevens, sendo também um traço estruturante do poema mais conhecido (mas não o melhor) de T. S. Eliot, "A terra desolada”, de 1922, no qual os ritos e mitos pagãos da fertilidade se convertem na possibilidade de redenção da modernidade poética norte-americana, já ressentida da morte de Deus e descrente das poéticas clássica e romântica. Poderíamos pensar, com Octavio Paz, nesta ênfase de Stevens e Eliot na religiosidade pagã como uma permanência do sentimento religioso face à descrença modernista na religião, sobretudo no Cristianismo, diante do qual a atitude de Stevens, como de outros modernistas anglófonos, se-

de Harvard da virada do século: Wallace Stevens." A tradução deste e de todos os outros textos originalmente em inglês ou espanhol é de minha autoria. A tradução dos poemas utilizada é a de Paulo Henriques Britto. 
SANTOS, A. C. A imaginação como metafísica: uma leitura do poema “0 percurso de um particular", de Wallace Stevens

ria híbrida, denotando um certo paradoxo da modernidade em relação ao Cristianismo: "Negação da religião: paixão pela religião. Cada poeta inventa sua própria mitologia e cada uma dessas mitologias é uma mistura de crenças diferentes, mitos desenterrados e obsessões pessoais." (1974, p. 31).

A junção desses dois aspectos da filosofia de Santayana na poesia de Stevens pode ser claramente percebida no poema "Sunday Morning" / "Manhã de domingo" que, embora pertença ao livro inaugural de Stevens, Harmonium, já "...anuncia, pela primeira vez, um grande poeta em plena posse de seus poderes". No poema, o eu lírico “...thinks about the death of Jesus and the basic tenets of Christianity..."3 (REHDER, 2007, p. 795) e se pergunta sobre a personagem do poema, uma mulher, "Shall she not find in comforts of the sun, / In pungent fruit and bright, green wings, or else / In any balm or beauty of the earth, / Things to be cherished like the thought of heaven?“4 (STEVENS, 1987, p. 26).

Mais importante, entretanto, do que esta vertente imagético-pagã na poesia de Stevens é a preocupação constante do poeta com as "questões quasi-filosóficas" (PERKINS, 1994, p. 288), que poderiam ser localizadas nas complexas relações entre a realidade e a imaginação, o "verdadeiro tema" (REHDER, op. cit., p. 708) que perpassa toda a poesia de Stevens.

Este "verdadeiro tema" de Stevens deve ser abordado em duas etapas. Em primeiro lugar, o interesse de Stevens pela realidade toma a forma de uma curiosidade não somente em torno das coisas que, ao nosso olhar se tornam mais vivas e presentes, como diria o próprio poeta (apud PERKINS, 1994, p. 289), mas acerca da natureza e suas estações, como se pode notar já nos títulos de alguns de seus livros, como Transport to Summer (1947) e The Auroras of Autumn (1950). Suas convicções “...had not changed in the years since Harmonium, but now [o crítico se refere ao momento da publicação de Ideas of Order, em 1935] he dealt more

\footnotetext{
3 “...reflete sobre a morte de Deus e os princípios básicos do Cristianismo."

4 "Por que não encontrar prazer no sol, / No odor das frutas, brilho das asas verdes, / Em qualquer outro bálsamo terreno, / Tão caro quanto o próprio paraíso?"
} 
SANTOS, A. C. A imaginação como metafísica: uma leitura do poema "O percurso de um particular", de Wallace Stevens

persistently and more directly with the loss of religious belief and the consequences of that loss." ${ }^{5}$ (PERKINS, 1994, p. 282-3), ou seja, Stevens, assim como o Eliot de The Waste Land, tem a plena consciência da morte de Deus mas, diferentemente do primeiro, não se volta ao misticismo cristão, e sim aprofunda seu interesse no ciclo das estações, que chegam a se tornar "a mode of survival, for a poet who found himself for the most part estranged from the supporting ties of family (parents, wife, siblings, daughter), friendships or religious faith."6 (LENSING, 2007, p. 2746).

Em outras palavras, Stevens buscava no ciclos sazonais da natureza uma espécie de correspondência com os seus estados de alma e não é difícil perceber a relação, como o aponta Lensing (op. cit., p. 2771 et passim), entre o outono e o inverno e os sentimentos de partida, deslocamento e destituição, assim como entre a primavera e o verão e os sentimentos de celebração, deleite e subjetividade reemergente (p. 2864 et passim). Porém, mais do que correlatos objetivos, as estações da natureza - assim como a realidade tout court - representavam para o poeta o desafio de encontrar uma ordem ou um padrão na mobilidade constante do real. 0 poeta se refere a este intróito como uma ordem superposta pela mente à profusão da natureza, como podemos ver nos versos finais de "Anecdote of the Jar" / "Anedota (sic) do jarro": "Oh! Blessed rage for order, pale Ramon, / The maker's rage to order words of the sea, / Words of the fragrant portals, dimly-starred, / In ghostlier demarcations, keener sounds." (STEVENS, 1987, p. 58).

Esta superimposição da mente à natureza nos leva à segunda etapa na abordagem das relações entre realidade e imaginação na poesia de Stevens, que é o papel da mente em sua poética. Sendo o acesso direto

\footnotetext{
5 “...não haviam mudado desde os anos de Harmonium, mas agora ele tratava mais direta e persistentemente da perda da crença religiosa e das consequências desta perda."

6 "um modo de sobrevivência para um poeta que se viu em grande parte estranho aos laços de apoio familiares (pais, esposa, irmãos, filha), amizade e fé religiosa."

7 “Ah, pálido Ramon, abençoado ímpeto / De ordem, ânsia do criador de ordenar / Palavras do mar, de portais fragrantes, / Estrelados, de nós mesmos, nossa origem, / Em espectrais demarcações, sons mais pungentes."
} 
SANTOS, A. C. A imaginação como metafísica: uma leitura do poema “O percurso de um particular", de Wallace Stevens

à realidade uma eterna impossibilidade, Stevens acredita não haver outra possibilidade humana senão acreditar naquilo mesmo que criamos, i.e., no mundo real como uma possibilidade co-extensiva à nossa mente. Acreditemos nela ou não, a dimensão imaginativa da realidade é algo que não se pode negar, como o poeta afirma em um de seus poemas mais famosos, "The Idea Of order at Key West" / "A ideia de ordem em Key West": "She was the single artificer of the world / In which she sang. And when she sang, the sea, / Whatever self it had, became the self / That was her song, for she was the maker. Then we, / As we beheld her striding there alone, / Knew that there never was a world for her / Except the one she sang and, singing, made."8 (STEVENS, 1987, p. 58).

A mente, portanto, é o grande artífice do mundo e cria a realidade a partir da experiência sensitiva, que ela ordena e orienta. Apesar de um pouco longa, esta citação esclarece bastante a função da mente na poesia de Stevens:

As creatures that interpret experience mentally, we have no choice but to believe in the mind's made-up version of reality, whether the reality is material (tables and tress, for example) or spiritual (God, Goodness, Truth, Beauty). Some believers, perhaps the majority, distract themselves from the fictional nature of their belief-objects. Other acknowledge the epistemological quandary but are satisfied that their fictions are "true" in the sense that they correspond closely to a presumed reality. Belief, after all, entails a tolerance for mystery. Few people are prepared to take the final step with Stevens, to embrace what he called "the nicer knowledge of / Belief, that what it believes in is not true." (BATES, 2007, p. 1225).

\footnotetext{
8 "Ela era a única artífice do mundo / Em que cantava. E, ao cantar, o mar, / Fosse o que fosse antes, se tornava / 0 ser do canto dela, a criadora. E nós, / Ao vê-la esplêndida e sozinha, compreendemos / Que nunca houve para ela outro mundo / Senão aquele que, ao cantar, ela criava."

9 "Como criaturas que interpretam a experiência mentalmente não temos outra escolha senão acreditar na versão da realidade criada pela mente, seja esta realidade material (mesas e árvores, por exemplo) ou espiritual (Deus, o Bem, a Verdade e a Beleza). Alguns crentes, talvez a maioria, se distraem da natureza ficcional de seus objetos de crença. Outros reconhecem o dilema epistemológico mas estão satisfeitos que a sua ficção seja "verdadeira", no sentido de que elas estão muito próximos de uma realidade presumida.
} 
SANTOS, A. C. A imaginação como metafísica: uma leitura do poema "O percurso de um particular", de Wallace Stevens

Sendo a mente a criadora da realidade, a poética de Stevens poderia muito bem se aproximar da poética romântica de Coleridge e Worsdworth ou da filosofia Kantiana, não fosse sua insistência na realidade da mente e, sequitur, do mundo. Critchley (2005, p. 347) propõe justamente a inversão da afirmação de Schlegel de que sem poesia não há realidade e afirma, a respeito da poesia de Stevens, que também se poderia dizer que sem realidade não há poesia.

\section{Imaginação e metafísica}

Esta ênfase no real em suas variadas nuances e transformações dá o contrapeso a uma tendência cerebral, mallarmeana, de sua poesia, criando uma equação, muito particular à sua poética, entre a generalidade da abstração e as particularidades do mundo. Critchley (2007, p. 1250) vê nesta equação um equilíbrio entre a tendência ao idealismo e ao pragmatismo, equilíbrio que pode ser visto em toda a sua poesia, mas que nas três direções apontadas pelo poeta para o exercício da "ficção suprema" se tornam mais claros, ou seja, nos imperativos de abstração, mudança e prazer: "It Must Be Abstract"/"Deve Ser Abstrata"; "It Must Change" / "Deve Mudar" e "It Must Give Pleasure"/ "Deve Dar Prazer" (STEVENS, 1987, p. 117 et passim)

Este equilíbrio toma, na poesia de Stevens, a forma de um diálogo constante e sempre cambiante entre a "afirmação diretamente reflexiva / straightforward reflective utterance" e a sua imagética fundada nas cenas, pessoas e imagens do cotidiano (PERKINS, 1994, p. 294). Ainda nas palavras de Perkins, “If his imagery is one main source of Steven's power, the other, complementing this concrete, imaginative tendency, lies in the active play of his intellect." ${ }^{10}$ (op. cit., p. 296).

\footnotetext{
À crença, portanto, se segue uma tolerância para o mistério. Poucos estão preparados para dar o passo final com Stevens e abraçar o que ele chamou de "o melhor conhecimento da / Crença, de que aquilo em que ela acredita não é verdadeiro."

10 "Se a sua imagética é uma fonte principal de poder de Stevens, a outra, complementando esta tendência concreta, imaginativa, está no jogo ativo do intelecto"
} 
SANTOS, A. C. A imaginação como metafísica: uma leitura do poema “O percurso de um particular", de Wallace Stevens

A imaginação tem o papel, neste equilíbrio, de organizar a "ficção suprema”, isto é, de encontrar um padrão na profusão do real e imaginá-lo sob a forma de imagens. Não está distante, portanto, do que dizia Baudelaire acerca da imaginação em seu texto sobre o Salão de 1859: "Ela decompõe toda a criação, e, com os materiais acumulados e dispostos conforme as regras das quais não podemos encontrar a origem senão no mais profundo da alma, ela cria um mundo novo, produz a sensação de um mundo novo." (1993, p. 94). Criar um mundo seria o mesmo que, na poesia de Stevens, pensá-lo, ação inevitável da mente sobre o real; criar um mundo novo, porém, seria imaginá-lo, atividade fundamental da poesia.

Ao tratar a mente como formadora de mundos e a imaginação como criadora de novos mundos, pode parecer, à primeira vista, que Stevens flerta ou se aproxima dos românticos - Stevens teve forte influência de Wordsworth e Coleridge -, mas a impressão se desfaz ao lermos o que o poeta diz em um dos ensaios da coletânea The Necessary Angel: Essays on Reality and the Imagination, primeiramente publicada em 1942:

The imagination is one of the great human powers. The romantic belittles it. The imagination is the liberty of the mind. The romantic is a failure to make use of that liberty. It is to imagination what sentimentality is to feeling. ${ }^{11}$ (1951, p. 138)

Ao mesclar imaginação com sentimentalismo, os românticos a emprobreceram, o que leva o poeta a se distanciar dos primeiros pelo fato de acreditarem no caráter divino da imaginação, enquanto Stevens vê toda crença como fictíticia. Imbuído do caráter niilista que dominou o modernismo norte-americano da primeira metade do século passado, Stevens vê todas as crenças — religiosas, científicas, artísticas - como produtos da imaginação, o que confere a estas últimas uma dimensão existencial que extrapola as fronteiras do poético. Em sintonia com o

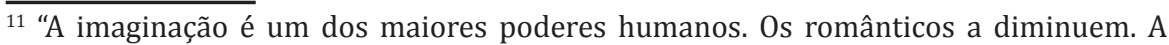
imaginação é a liberdade da mente. Os românticos falham em fazer uso desta liberdade. É para a imaginação o que o sentimentalismo é para o sentimento. É uma falha da imaginação assim como o sentimentalismo é uma falha do sentimento." 
SANTOS, A. C. A imaginação como metafísica: uma leitura do poema "O percurso de um particular", de Wallace Stevens

pensamento de seu contemporâneo teutônico, Martin Heidegger, mas sem qualquer contato ou influência de que se tenha notícia, Stevens acredita que a poesia cria os mundos que posteriormente serão pensados pela razão em sua modalidade científica.

Para os românticos ingleses a imaginação era o exercício individual da emoção ou da intuição (como preferiam os românticos de Jena) sobre objetos particulares, por meio dos quais o universal, absoluto ou divino poderia ser alcançado. Já para Stevens, o exercício da imaginação não afeta um homem ou um objeto, mas é o exercício da faculdade mesma. "Accordingly, when we think of the permeation of man's life by imagination, we must not think of it as a life permeated by a single thing but by a class of things." ${ }^{12}$ (op. cit., p. 144), isto é, devemos pensar a imaginação como permeando todas as instâncias da vida do homem, tais como a política, a religiosa, a familiar, etc. , como "uma atividade imaginativa que se difunde em nossas vidas" (op. cit., p. 149).

A imaginação cria mundos possíveis, "importa o irreal para dentro do que é real” (STEVENS, op. cit., p. 150), organiza a profusão material em imago mundi - a "imagem do mundo que nos concerne vitalmente" (op. cit., p. 151) -, possuindo inegavelmente uma dimensão vital, metafísica, a nossa "única pista para a realidade" (op. cit., p. 137), como pretendia o poeta. É por ela que podemos perceber "o normal no anormal, o oposto do caos no caos" (op. cit., p. 153)

Sendo uma instância profunda que antecede qualquer forma de conhecimento racional, a imaginação precede, como dirá também Octavio Paz n'O arco e a lira (1990, p. 147 et passim), tanto o pensamento racional quanto a "disposição divinizante" de que fala o poeta-crítico mexicano. As profundezas nas quais a imaginação poética navega não podem, portanto, ser verbalizadas diretamente e cabe ao vate se valer da linguagem para traduzi-las, deixando que o silêncio ontológico destas profundezas fale por meio de imagens poéticas. Assim se refere Stevens

12 "Assim, quando pensamos na vida do homem permeada pela imaginação, não devemos pensá-la como uma vida permeada por uma única coisa, mas por uma classe de coisas" 
ao valor da imaginação:

It is not the value of knowledge. It is not the value of faith. It is the value of the imagination. The poet tries to exemplify it, in part, as I have tried to exemplify it here, by identifying it with an imaginative activity that diffuses itself throughout our lives. I say exemplify and not justify, because poetic value is an institutional value and because values cannot be justified." ${ }^{13}$ (1951, p. 149)

Assim como Paz e Heidegger, e sobretudo este último, a imaginação, criando mundos e possibilitando o conhecimento racional tanto quanto a fé, equivale, para Stevens, à experiência da verdade, a verdade da arte que os modernistas norte-americanos do começo do século XX valorizaram como forma de resistência diante de um mundo já cético das verdades científicas, religiosas e até mesmo artísticas, no qual o niilismo que servira às vanguardas artísticas já havia se tornado o esteio maior de uma sociedade burguesa fundamentada no desenvolvimento tecnológico e na acumulação capitalista.

Sob a forte influência de Nietzsche, Stevens se afasta de uma idealização da verdade da arte, preferindo ver nesta verdade um caráter provisório, ficcional, no qual temos de acreditar mesmo sabendo que se trata de uma ficção. Trata-se de uma verdade que só poderia ser expressa pela imaginação poética em perene confronto com a riqueza do mundo natural e social, tentando encontrar o padrão, a recorrência, por meio de imagens que revelam o irreal no real, a verdade autêntica em meio à inautenticidade do cotidiano, como diria Heidegger. Tal verdade teria que seguir os preceitos de ser abstrata, mudar e dar prazer, como "Notes Towards a Supreme Fiction" / "Apontamentos para uma ficção suprema" explica de forma quase programática. Vale a pena destacarmos alguns

\footnotetext{
13 “Não é o valor do conhecimento. Não é o valor da fé. É o valor da imaginação. 0 poeta tenta exemplifica-lo, em parte, como eu tento exemplifica-lo aqui, identificando-o com uma atividade imaginativa que se difunde através de nossas vidas. Digo exemplificar, e não justificar, porque o valor poético é um valor intuitivo e os valores intuitivos não podem ser justificados."
} 
SANTOS, A. C. A imaginação como metafísica: uma leitura do poema "O percurso de um particular", de Wallace Stevens

versos do primeiro poema de cada parte como exemplo da verdade poética de Stevens. Comecemos com as duas primeiras estrofes do primeiro poema da primeira parte, "Deve ser abstrata":

Begin, ephebe, by perceiving the idea

Of this invention, this invented world,

The inconceivable idea of the sun.

You must become an ignorant man again

And see the sun again with as ignorant eye

And see it clearly in the idea of it. ${ }^{14}$

(STEVENS, 1987, 116)

0 poeta aconselha ao efebo que abstaria do real a sua ideia e que nela se fundamente, com a surpresa de quem vê pela primeira vez. Posteriormente, no poema, o poeta dirá que o sol, se visto em sua ideia, é limpo e pertence a um céu "'that has expelled us and our images.../...que nos baniu, com nossas imagens..." (STEVENS, 1987, p. 116).

0 primeiro poema da segunda parte, "Deve mudar", nos reserva a profusão do real em suas cores, perfumes e movimento. 0 poeta fala do velho serafim que aspirava o perfume das flores, das moças na Itália com flores nos cabelos, dos bandos de abelhas zunindo, imagens de "inconstant objects of inconstant causes / objetos inconstantes de inconstantes causas". A imaginação, como verdade poética, precisa acompanhar este movimento, precisa abstrair e buscar o padrão para formatar o real e conhecê-lo, "It means that the distaste we feel for this withered scene // Is that it has not changed enough. It remains / It is a repetition."15 (op. cit., p. 134)

A terceira parte, "Deve dar prazer", traz a resultante poética da tensão entre o pensamento abstrato que organiza, cataloga, entende, e o real, cuja imagética no poema aponta para o caos, a profusão e a inconstância. Sem precisar optar por uma ou outra forma de conhecimento, a imagina-

14 “Começa, efebo, percebendo a idéia / Desta invenção, deste mundo inventado, / A noção inconcebível de sol. // Tens de voltar a ser ignorante / E ver com o olho ignorante o sol / E vê-lo com clareza em sua idéia.

15 "O que nos incomoda nesta cena fenecida // É não mudar ela o bastante, ser sempre / A mesma." 
ção as aproxima sem dirimi-las de suas especificidades, como os estados poéticos de Valéry que podem, ao final e ao cabo, se transformar em elocuções poéticas ou proposicionais (1999, p. 196).

0 primeiro poema desta parte fala de "um mundo mais sensual", figurado por um vocabulário hedonista - cantar, exultar, falar, cantar de júbilo, sentir, gerar, luz e música - e imaginado, portanto, realizado. Os versos finais nos ajudam a entender melhor o prazer que Stevens conclama como o prazer da imaginação agindo sobre o mundo, como o circunspecto funcionário da Hartford Accident and Indemnity Company da qual chegou a ser vice-diretor - poetando solitariamente no recesso do lar, à noite, e imaginando, senão criando mundos possíveis para o seu próprio deleite, com a razão racional sempre a reboque das imagens de mundos possíveis:

On the image of what we see, to catch from that

Irrational moment its unreasoning,

As when the sun comes rising, when the sea

Clears deeply, when the moon hangs on the wall

Of heaven-haven. These are not things transformed.

Yet we are shaken by them as if they were.

We reason about them with a later reason. ${ }^{16}$

(STEVENS, op. cit., 151)

\section{III. "The Course of a Particular" / "O percurso de um pormenor"}

Today the leaves cry, hanging on branches swept by wind, Yet the nothingness of winter becomes a little less.

It is still full of icy shades and shapen snow.

\footnotetext{
16 "Na imagem que vemos, capturamos // Do instante irracional a não-razão, / Como ao nascer do sol, o mar clareando / Fundo, quando a lua paira na parede // Do céu. Tais coisas não são transformadas, / Porém nos abalam como se fossem. Pensamos nelas com razão tardia."
} 
SANTOS, A. C. A imaginação como metafísica: uma leitura do poema "O percurso de um particular", de Wallace Stevens

The leaves cry... One holds off and merely hears the cry.

It is a busy cry, concerning someone else.

And though one says that one is part of everything,

There is a conflict, there is a resistance involved;

And being part is an exertion that declines:

One feels the life of that which gives life as it is.

The leaves cry. It is not a cry of divine attention, Nor the smoke-drift of puffed-out heroes, nor human cry.

It is the cry of leaves that do not transcend themselves,

In the absence of fantasia, without meaning more Than they are in the final finding of the ear, in the thing Itself, until, at last, the cry concerns no one at all. (STEVENS, 1987, p. 194) ${ }^{17}$

O poema que ora discutiremos faz parte da obra póstuma de Stevens, tendo sido publicado em 1957, dois anos após a morte do autor. Apesar da conversão do poeta - um "materialista convicto" (BRITTO, 1987, p. 14) - ao catolicismo quando a sua situação de saúde piorou - Stevens havia sido diagnosticado com um câncer incurável em 1955, ano de sua morte - este fato não teve repercussão na poesia do poeta, que algum tempo antes havia declarado em uma de suas cartas: "I am not an atheist although I do not believe today in the same God in whom I believed when I was a boy."18 (apud JARRAWAY, 2007, p. 4324). Critchely (op. cit., p. 21) vê a sua conversão como "the act of a dying, lonely man who confessed to

\footnotetext{
17 "Hoje as folhas gritam, em galhos que vento varre, / Porém o nada do inverno atenua um pouco, / Ainda pleno de sombras frias, neve moldada. // As folhas gritam...Nos contemos, e ouvimos, apenas, / É um grito prático, que diz algo a outro alguém. / E embora nos julguemos parte do todo, // Há um conflito, uma resistência aqui, / E ser parte é um esforço que declina: / Sentimos a vida que gera a vida tal qual é. // As folhas gritam. Não é grito de atenção divina, / Nem fumaça de herói que se apagou, nem grito humano. / É grito de folhas que não se transcendem, // Na ausência da fantasia, que só quer dizer / Que estão na descoberta última do ouvido, coisa em si, / Até que o grito, não diz nada a ninguém."

18 "Eu não sou um ateu, embora eu não acredite hoje no mesmo Deus em que eu acreditava quando garoto."
} 
SANTOS, A. C. A imaginação como metafísica: uma leitura do poema “0 percurso de um particular", de Wallace Stevens

a certain "emptiness in his life' and who hadn't been on speaking terms with his wife for years." 19

"O percurso de um pormenor" é um dos poemas de Stevens que têm o ciclo sazonal como referência e que tematizam o inverno. Além de ressaltar os sentimentos de partida, deslocamento e destituição, como dissemos anteriormente ( $c f$. p. 5), poderíamos dizer deste poema que realiza um trajeto que inicialmente poderíamos associar à negatividade filosófica, isto é, à atitude de enxergar na atividade da mente uma ação e um alcance limitado no conhecimento do mundo e na linguagem, uma tentativa inglória de expressão do inexprimível. Termos como "nada", "resistência”, "declina”, "ausência”, além do uso constante do advérbio de negação (não ou não/nem) indicam um caminho poético de uma experiência fundamentalmente mental e poética da realidade.

0 poema fala de folhas no inverno, expostas ao vento frio e pendentes em galhos cobertos de neve, folhas que não transcendem a si mesmas, i.e., que cumprem seu mister de ser realidade crua, "coisas como elas são", diria Stevens. Porém, estas folhas emitem um grito ("cry") que não é humano nem divino, sendo que esta afirmação (de que as folhas gritam) é feita em três das cinco estrofes do poema, cada vez de forma diferente ("Hoje as folhas gritam", na primeira estrofe; "As folhas gritam...", na segunda e "As folhas gritam.", na terceira). A mudança na elocução desta percepção parece corresponder a uma mudança de atitude e de pensamento que assinala a trajetória que o poema perfaz.

A afirmação de que as folhas gritam e de que este grito bruto das coisas despidas da "fantasia" ("fancy"20) só é plausível pelo fato de que há ouvidos para este grito. Ouvidos, não necessariamente pessoas, uma vez que o humano é como que destituído de sua função como agente

19 "o ato de um homem solitário e moribundo que confessou "um certo vazio" em sua vida e que não falava com sua esposa há anos."

${ }^{20} 0$ tradutor acertadamente traduz "fancy" por "fantasia", e não por imaginação, uma vez que as duas traduções seriam possíveis. Porém, no contexto do poema Stevens usa "fancy" de maneira semelhante ao modo como Coleridge usa o termo na sua Biographia Literaria, para se referir ao sentido comum da imaginação, do qual ele procura se afastar. 
SANTOS, A. C. A imaginação como metafísica: uma leitura do poema "O percurso de um particular", de Wallace Stevens

da escuta e manifesto na sinédoque do ouvido, um ouvido coletivo que é referido por meio da primeira pessoa do plural ("Nos contemos e ouvimos", "nos julguemos", "sentimos"). Lensing (op. cit., p. 2839) se refere aos poemas de "inverno absoluto" como possuindo "a mysterious, almost ghostlike presence, lingering in the wake of human effacement". ${ }^{21}$

Trata-se, então, de um humano destituído de suas características fundamentais, ao qual só restou uma escuta incompreensível, desumana. Aparentemente pós-apocalíptico, este sujeito nos parece mais afim ao sujeito heideggeriano, quando o filósofo afirma que a natureza do pensar/poetar (para o filósofo sinônimos) é uma escuta do ser que, para o poeta, é constituído de linguagem, uma linguagem autêntica, original, comparada à qual a fala comunicativa é limitada e circunstancial. Dirá Heidegger em texto da década de 50, que “[a] grandeza de uma obra consiste, na verdade, em que o poema pode negar a pessoa e o nome do poeta." (2003, p. 13)

$\mathrm{Na}$ primeira estrofe o grito das folhas surge em meio ao nada do inverno, à frieza e aparente rejeição do humano que uma paisagem campestre no inverno do hemisfério norte parece produzir. 0 grito é prático, diz algo a outras pessoas, diz algo às pessoas, que desejam ouvir, apreender este elemento natural, não humano do mundo, esta diferença radical que o homem busca domesticar e acumular. As sombras frias e a neve moldada à forma das coisas (árvores, galhos, folhas) são portadoras do nada, do vazio de humanidade que o inverno simboliza. 0 elemento humano, que pensa e ouve, aparece na forma do advérbio temporal "hoje", que indica um sujeito lírico percipiente diante do nada da natureza que continuará - como o último verso do poema mostra - indiferente ao ímpeto humano de transformar o desconhecido em "bela natureza", estetizada e transformada em extensão do humano. Critchely afirma que "nothingness-as-something remains the only way the poet can accura-

21 "uma presença misteriosa, quase fantasmal, que permanece com a obliteração do humano". 
tely codify the pure and undistorted state of being"22 (op. cit., p. 2827).

A segunda estrofe se inicia com uma variação da afirmação "Hoje as folhas gritam" para "As folhas gritam...", mudança que parece dissipar o humano, deixando o natural à sua própria mercê. As folhas gritam, gritavam e continuarão a gritar, independentemente da presença do sujeito lírico que, neste poema assim como na poética de Stevens, parece tomar outras feições que o distanciam do sujeito criado pelo humanismo, como afirmou o poeta em uma de suas cartas, "the more I see of humanism the less I like it"23 (JARRAWAY, op. cit., p. 4318).

Na terceira estrofe, o esforço humano em ser "parte do todo", em tentar comungar com a natureza aquilo que não pode ser compartilhado, isto é, sua estranheza radical em relação ao humano, é uma caricatura poética do esforço humanista em criar um mundo harmônico no qual o humano e o natural se complementam e interagem reciprocamente. 0 esforço do poeta em recuperar o divino pela via da fertilidade pagã e harmonizá-lo com o humano em seu livro de estréia, Harmonium também presente no Eliot de The Waste Land - se transformará, na sua poesia posterior, em abandono da harmonia e ênfase crescente no papel da imaginação em criar ordens fictícias para possibilitar seu contato com o real.

0 esforço de uma união transcendental com a natureza - tão eloquente em Emerson e Whitman - gera conflito, resistência, pois "é um esforço que declina", novamente apontando para a limitação da estetização ou do conhecimento racional em tratar com o elemento irredutível da natureza. No lugar do conhecimento ou da estetização em que tal esforço resultaria, temos o recolhimento do humano a um sentir "a vida do que gera a vida tal qual é" e gostaríamos de chamar a atenção para o fato de que o que gera a vida não é personificado, como no Cristianismo. Pelo contrário, o que gera a vida é "aquilo" ("that"), o que nos leva a crer que

\footnotetext{
22 "o nada-como-algo continua a ser a única forma de o poeta codificar com clareza o estado puro e não distorcido do ser"

23 "quanto mais eu vejo do humanismo, menos eu gosto dele"
} 
SANTOS, A. C. A imaginação como metafísica: uma leitura do poema "O percurso de um particular", de Wallace Stevens

Stevens esteja se referindo ao ser, hipótese que parece ser confirmada pela constante reflexão sobre o ser em seus poemas. (EEKHOUT, 2007).

A quarta estrofe se inicia com uma segunda modulação da afirmação de que as folhas gritam, desta vez dilapidada do advérbio temporal e das reticências que parecem sugerir o curso per se das coisas da natureza. Neste momento a sugestão já está elaborada na forma de uma afirmação peremptória, à qual vêm se somar as tintas do niilismo modernista norte-americano, com a referência à "fumaça de herói que se apagou” ou à retirada nietzscheniana de deus. As possíveis correspondências entre o real/natural e uma ordem superior, que em Baudelaire tomam a forma de uma teoria das correspondências na tradição dos místicos europeus e na qual "[o] mundo visível seria assim uma correspondência de um mundo invisível e superior, uma imagem imperfeita e caduca desse céu cuja conquista o poeta deveria empreender" (JUNQUEIRA, 1985, p. 58), em Stevens são esvaziadas de seu teor místico e a transcendência é outorgada à imaginação que, como já dissemos, assume uma dimensão metafísica.

0 grito das folhas acena, então, não para uma ordem superior e transcendente, mas para a natureza que não transcende a si mesma, sendo impermeável à abstração humana, como explica Critchley:

It is simply the cry of leaves that appear to reach out to us, but which do not transcend themselves. It is the cry of matter mattering regardless of whether it matters to us. The leaves are, but they are not for us. All that they mean, like the howling of the dove, is that which is found in the ear that hears, in the absence of fantasia, without the conjurings of imagination. The poet hears the thing itself without the meaning-making work of the imagination..$^{24}$ (op. cit., p. 71) [ênfase do autor]

\footnotetext{
24 "É simplesmente o grito de folhas que parecem nos alcançar, mas que não transcendem a si mesmas. É o grito da matéria se materializando ("it is the cry of matter mattering") sem se importar conosco. As folhas são, mas não são para nós. Tudo o que elas querem dizer, como o pio da pomba, é aquilo que é encontrado no ouvido que ouve, na ausência de fantasia, sem as elaborações ("conjurings") da imaginação. 0 poeta ouve a coisa sem o trabalho de significação da imaginação."
} 
SANTOS, A. C. A imaginação como metafísica: uma leitura do poema “0 percurso de um particular", de Wallace Stevens

A "descoberta última do ouvido, coisa em si" é a resignação diante da impossibilidade de ser parte do todo que a imaginação, como ficção necessária que engrendramos como única possibilidade de pensar - e, consequentemente, fazer existir — a realidade, se torna uma ficção suprema, poética.

Por fim, na última estrofe há o abandono total das coisas a si mesmas, indiferentes a nós, como o mundo que os existencialistas percebem como indiferente e até mesmo hostil à consciência. 0 grito, que na segunda estrofe havia significado algo para "outro alguém", agora "não diz nada a ninguém", seu silenciamento não é imposto, a natureza não é dominada ou subjugada à simbolização ou à tecnologia, mas permanece impermeável ao humano, no fundo do seu mistério e do seu segredo, de onde continuarão a brotar todas as mitologias e todos os poemas vindouros.

\section{Conclusão}

Stevens parece conjuminar as duas tendências da poesia moderna apontadas por Friedrich e retomadas por Hamburguer, a que poderíamos nos referir como a tendência à "destruição da realidade" e a tendência à criação de "uma poesia repleta de coisas", na qual as possibilidades da linguagem como forma de acesso ao real são exploradas (HAMBURGUER, 2007, p. 45). Stevens tem a consciência modernista da linguagem como locus onde a ficção imaginativa e o grito das coisas se encontram, sendo esse locus esvaziado de sua transcendência emersoniana ou de sua relação snapshot, fotográfica, com a realidade, como em seu contemporâneo e amigo pessoal, William Carlos Williams. Assim como seus contemporâneos modernistas, Stevens também compartilhava "uma preocupação constante com as possibilidades e limites da linguagem, incluindo a contradição inerente a ela como o material da poesia" (op. cit., p. 52).

Uma das contradições mais marcantes da poesia moderna é o esforço 
SANTOS, A. C. A imaginação como metafísica: uma leitura do poema "O percurso de um particular", de Wallace Stevens

sisífico em dar sentido ao mundo por meio da linguagem, projeto frustrado de início pela consciência existencialista de que não há sentido prévio do mundo e pela percepção de que é a linguagem que torna o mundo acessível à consciência. Elaborar uma linguagem que acolha a tentativa de dar sentido a uma experiência de mundo em que não há sentidos ou valores prévios foi a tarefa das vanguardas literárias e artísticas do século XX.

Stevens se ressente desta impossibilidade de sentido do mundo mas, diferentemente das vanguardas, não busca nas experiências formais uma saída para o inevitável fracasso da linguagem em reatar o homem ao mundo, o homem à sua consciência ou esta consciência ao mundo. 0 "métier de nada" que Stevens praticou por meio da imaginação como metafísica implica em uma aceitação do fracasso, da hubris como derrota humana diante do inacessível, fracasso da razão e da "fantasia". Somente a imaginação pode definir a verdade essencial, não "the truth as it is... but the truth as we see it." ${ }^{25}$ (STEVENS, 1951, p. 147), isto é, uma verdade estética que permite a posteriori o cálculo e a razão.

Peço licença ao leitor para concluir com uma citação um pouco mais longa da obra de Michael Critchley, Things Merely Are: Philosophy in the Poetry of Wallace Stevens, que define com lucidez o fracasso poético de Wallace Stevens, um fracasso que fez dele um dos mais importantes poetas norte-americanos do séclo XX:

Stevens's poetry fails. Perhaps all modern poetry fails. And maybe this is the point. In my view, poetry written in the wake of romanticism is defined by an experience of hubris and failure, of hubris presaging failure. For example, at the moment of saying "God is dead, therefore I am", it is utterly unclear in what the "I am" consists. It is a mere leaf blown by the wind, a vapour, an ember, a bubble. The moment of the egos assertion, in selling up to fill a universe without God, is also the point at which it shrinks to insignificance.

$[\ldots]$

25 "não a verdade como ela é [...] mas a verdade como a vemos" 
Yet, failure contains an imperative, something which I think is suggested in Stevens's late lyrics, what I called above the métier of nothingness. Such a nothingness prescribes a task and requires a craft, namely the endless activity of description in the full awareness of failure. Failure here is defined by the courage to persist with failure. As Beckett would say, "try again, fail again, fail better." ${ }^{26}$ (CRITCHLEY, op. cit.p. 137)

\section{Referências bibliográficas}

BATES, M. J. "Stevens and the supreme fiction" In SERIO, J. N. (Ed.) The Cambridge Companion to Wallace Stevens. Cambridge: Cambridge University Press, 2007. [Edição eletrônica Kindle]

BAUDELAIRE, C. “Salão de 1859” In: Obras Estéticas. Filosofia da imaginação criadora. Rio de Janeiro: Vozes, 1993.

BRITTO, P. H. Wallace Stevens. "Introdução”. São Paulo: Companhia das Letras, 1987.

CRITCHLEY, S. Things Merely Are. Philosophy in the Poetry of Wallace Stevens. New York: Routledge, 2005 [Edição eletrônica Kindle]

EECKHOUT, B. "Stevens and Philosophy"In SERIO, J. N. (Ed.) The Cambridge Companion to Wallace Stevens. Cambridge: Cambridge Univer-

\footnotetext{
26 "A poesia de Stevens fracassa. Talvez toda poesia moderna fracasse. E talvez este seja o ponto. Para mim, a poesia escrita no esteio do romantismo é definida por uma experiência da hubris e do fracasso, da hubris como presságio do fracasso. Por exemplo, no momento de dizer "Deus está morto, portanto eu sou", é completamente obscuro no que o "eu sou" consiste. É uma mera folha soprada pelo vento, um vapor, uma brasa, uma bolha. 0 momento da assertiva do ego, ao se inflar para preencher um universo sem Deus, é também o ponto no qual ele se encolhe à insignificância.

$[\ldots]$

Entretanto, o fracasso contém um imperativo, algo que acredito estar sugerido na lírica posterior de Stevens, que eu chamei de métier de nada. Tal nada prescreve uma tarefa e requer uma habilidade, qual seja a atividade infinda de descrição sob a plena consciência do fracasso. Fracasso aqui é definido como a coragem de persistir com o fracasso. Como Beckett diria, 'tente novamente, falhe novamente, falhe melhor'”. (op. cit., p. 137)
} 
SANTOS, A. C. A imaginação como metafísica: uma leitura do poema "O percurso de um particular", de Wallace Stevens

sity Press, 2007. [Edição eletrônica Kindle]

HEIDEGGER, M. A caminho da linguagem. Rio de Janeiro: Petrópolis/ Bragança Paulista: Editora universitária São Francisco, 2003.

HAMBURGUER, M. A verdade da poesia. Tensões na poesia modernista desde Baudelaire. São Paulo: Cosac Naify, 2007.

JUNQUEIRA, I. “A arte de Baudelaire” In: BAUDELAIRE, C. As flores do mal. Tradução, introdução e notas de Ivan Junqueira. Rio de Janeiro: Nova Fronteira, 1985.

LENSING, G. S. "Stevens' seasonal cycles" In SERIO, J. N. (Ed.) The Cambridge Companion to Wallace Stevens. Cambridge: Cambridge University Press, 2007. [Edição eletrônica Kindle]

PAZ, Octavio. Los Hijos del Limo. Del Romantismo a la vanguardia. Barcelona: Editorial Seix Barral S. A., 1974.

. El Arco y la Lira. El poema. La revelación poética. Poesía y Historia. Séptima reimpresión. Mexico: Fondo de cultura Económica, 1990. PERKINS, D. A History of Modern Poetry. From the 1890's to the High Modernist Mode. Cambridge: Harvard University Press, 1976.

. A History of Modern Poetry. Modernism and After. $4^{\text {th }}$ Printing. Cambridge: Harvard University Press, 1994.

REHDER, R. "Stevens and Harmonium” In SERIO, J. N. (Ed.) The Cambridge Companion to Wallace Stevens. Cambridge: Cambridge University Press, 2007. [Edição eletrônica Kindle]

STEVENS, W. Poemas. Tradução e introdução de Paulo Henriques Britto. São Paulo: Companhia das Letras, 1987.

. The Necessary Angel. Essays on Reality and the Imagination. Random house, Inc., 1951.

VALÉRY, P. "Poesia e pensamento abstrato” In: Variedades. São Paulo: Iluminuras, 1999. 